\title{
Attitude and experience of neurologists towards percutaneous endoscopic gastrostomy: an Egyptian study
}

\author{
Sherien Farag ${ }^{1}$, Shady S. Georgy ${ }^{1}$, Mai Fathy ${ }^{1}$, Ahmed elSadek ${ }^{1}$ and Khaled O. Abdulghani ${ }^{2^{*}}$ (D
}

\begin{abstract}
Background: Dysphagia is a common symptom among various neurological diseases. Guidelines recommend gastrostomy insertion for prolonged dysphagia with lower rate of intervention failure encountered with percutaneous endoscopic gastrostomy (PEG) as compared to nasogastric tube insertion.

Methods: Neurology consultants only were included and completed a self-administered questionnaire concerning their practice backgrounds and previous experience with PEG feeding during their practice.

Results: Ninety-eight percent stated that they would recommend PEG for patients with prolonged need of nasogastric feeding. However, only 88\% actually referred patients to perform PEG, with the cerebrovascular disorders being the most common cases to be referred. The main barriers the surveyed neurologists faced were family resistance and financial reasons (53.5\%). Interestingly, younger neurologists practicing for less than 15 years referred patient to perform PEG significantly more frequent than older ones $(p=0.01$ ). About $18 \%$ of our sample confirmed the lack of sufficient knowledge about the benefits of PEG feeding, and only $22 \%$ previously attended scientific sessions about the benefits and indications of PEG.

Conclusion: Based on our study, we recommend that PEG should be more encouraged in indicated neurological cases. Scientific sessions targeting neurologists and public awareness about the benefits of PEG and its relatively infrequent complications are highly demanded.
\end{abstract}

Keywords: Percutaneous endoscopic gastrostomy, Nasogastric tube, Dysphagia, Neurology practice, Attitude

\section{Introduction}

Dysphagia is a common symptom among various neurological diseases. Neurogenic dysphagia can result from either upper motor or lower motor neuron affection [1]. Dysphagia significantly increases the morbidity and mortality from neurological disorders through complications such as dehydration, malnutrition, and aspiration pneumonia [2]. Prolonged dysphagia is encountered not only in patients with chronic neurological diseases but also in about $10 \%$ of acute stroke survivors whose dysphagia extends more than 2 weeks in duration [3].

\footnotetext{
* Correspondence: khaled.abdulghani@med.helwan.edu.eg

${ }^{2}$ Neurology Department, Helwan University School of Medicine, Cairo, Egypt Full list of author information is available at the end of the article
}

Early screening and multidisciplinary approaches are recommended for effective management of neurogenic dysphagia [4]. Guidelines recommend nasogastric tube (NGT) insertion for dysphagia and inability to obtain adequate caloric intake for less than 2 weeks and gastrostomy insertion for prolonged dysphagia as early as 14 days and as late as 4-6 weeks [5] with lower rate of intervention failure encountered with percutaneous endoscopic gastrostomy (PEG) as compared to NGT insertion [6].

Despite the abovementioned recommendations, clinicians noticed a practice gap regarding the use and recommendation of gastrostomy among patients with prolonged neurogenic dysphagia $[7,8]$ with a documented variable rates of feeding tube insertion among
Springer Open (c) The Author(s). 2020 Open Access This article is licensed under a Creative Commons Attribution 4.0 International License, which permits use, sharing, adaptation, distribution and reproduction in any medium or format, as long as you give appropriate credit to the original author(s) and the source, provide a link to the Creative Commons licence, and indicate if changes were made. The images or other third party material in this article are included in the article's Creative Commons licence, unless indicated otherwise in a credit line to the material. If material is not included in the article's Creative Commons licence and your intended use is not permitted by statutory regulation or exceeds the permitted use, you will need to obtain permission directly from the copyright holder. To view a copy of this licence, visit http://creativecommons.org/licenses/by/4.0/. 
different attending physicians [9]. In order to understand more about this issue, Jaafar and colleagues, in 2015, administered a questionnaire to test the responses and attitude of 180 Malaysian healthcare professionals regarding gastrostomy feeding [10]. A more recent study was conducted by Gieniusz and colleagues to test physicians' attitude towards feeding tube insertion among dementia patients [7].

To our knowledge, there is no available literature discussing the attitude of neurologists for feeding tubes among patients with neurological disorders in any of the Middle East countries. Therefore, our goal is to explore the attitude, experience, problems, and complications that can explain such clinical practice gap regarding the use of gastrostomy in patients with prolonged neurogenic dysphagia.

\section{Methods}

This study was a cross-sectional study. One hundred neurology consultants were included in this study and completed a self-administered questionnaire (Table 1). The questionnaire was divided into sections. The first section included years of experience, area of practice, and possible barriers for PEG. The second section included questions concerning previous experience with PEG regarding rate, time, and causes of referral as well as experienced complications and degree of satisfaction regarding the overall outcome.

\section{Statistical analysis}

Descriptive analyses were conducted by frequency distribution for the categorical variables and means \pm standard deviation for continuous variables. The chi-square test was used to compare categorical variables, with statistical significance set at $p<0.05$.

\section{Results}

One hundred neurologists were interviewed with mean years of experience of $15.12 \pm 9.38$ years. Among those neurologists, $78 \%$ practiced mainly in university hospitals, $14 \%$ in private hospitals, and $8 \%$ in other hospitals (5 in the Ministry of Health hospitals, 2 in army and police hospitals, and 1 in health insurance hospital). Among our participants, $76 \%$ practiced in Cairo and Giza, 14\% in Upper Egypt, and 10\% in Lower Egypt (4\% in Delta, $4 \%$ in Canal region, and 2\% in Alexandria).

Participants were asked about their main field of practice: $40 \%$ were mainly interested in stroke, $31 \%$ in general neurology, $13 \%$ in multiple sclerosis, $7 \%$ in epilepsy, $3 \%$ in neuromuscular, $2 \%$ in movement disorders, $2 \%$ in headache, $1 \%$ in pediatric neurology, and $1 \%$ in neurorehabilitation.

Sixty-six percent of the participating neurologists were previously approached by a GIT specialist to suggest or offer PEG for their patients while only $22 \%$ previously attended a lecture or seminar about the benefits and indications of PEG. Ninety-eight percent stated that they would recommend PEG for patients with prolonged need of nasogastric feeding. However, only $88 \%$ stated that they actually referred patients to perform PEG.

We investigated the main barrier for offering PEG: participants were allowed to give more than one response, and 74 responses attributed the main obstacle to family resistance, 32 to fear of complications, 31 to lack of knowledge about the benefits of PEG, 19 to financial issues, and 14 to unavailability of well-trained GIT specialists, while only 3 responses accounted on previous unsuccessful experience and 1 was not convinced with its benefit. Further investigation for the main concern leading to family resistance (allowing more than one response) showed 63 responses accounting on fear that they will not be able to handle it and provide proper care, 45 for avoiding surgical procedures, and 20 to fear of altered body image.

Among our 88 neurologists previously referring patients to perform PEG, 55 (62.5\%) referred less than 10 patients, $13(14.77 \%)$ referred 11-20 patients, and 20 $(22.73 \%)$ referred more than 20 patients. On trying to associate these results with the years of experience practicing Neurology among those 88 neurologists, there was a statistically significant difference in favor of younger neurologists to refer a patient to perform PEG with a $p$ value of 0.01 (Table 2).

Thirty-nine (44.32\%) offer PEG on the first 2-4 weeks and $23(26.14 \%)$ at $5-8$ weeks while $26(29.54 \%)$ offer PEG after more than 8 weeks. The main reasons for referral (allowing more than one response) were preventing aspiration in 68 responses, improving the patient's quality of life in 55, malnutrition and weight loss in 34, prior positive experience in 22, being suggested by nutrition or GIT specialist in 12, and availability of PEG in 7 and only 2 performed PEG upon family request.

The most common diagnosis (allowing more than one response) was brain stem infarction in 69 responses, motor neuron disease in 40, dementia in 27, MCA infarction in 27, ICA infarction in 14, post-encephalitic sequel in 13, Parkinson's disease in 10, intracerebral hemorrhage in 7 , multiple sclerosis in 3 , and other causes in 5 ( 1 leukodystrophy, 2 brain tumor, 1 progressive supranuclear palsy, 1 post-arrest and hypoxicischemic encephalopathy). PEG was most commonly performed by gastroenterologists in $47(53.41 \%)$ patients followed by general surgeons in $33(37.5 \%)$ followed by interventional radiologists in $8(9.09 \%)$ patients.

Participants were asked to rate their average experience regarding the patient's outcome on a scale from 15 ( 1 being very unsatisfactory experience and 5 being a very satisfactory experience): $40(45.45 \%)$ rated their 
Table 1 Questionnaire regarding neurologists' experience regarding PEG

\section{Do you agree to participate? *Yes *No}

\section{If Yes, please proceed to answer the following questions}

1 -Years of practice? ---------- years

2-Main practice place?

*University hospitals

*Army and police hospitals

*Private hospital

*Health insurance hospitals

*Ministry of health hospitals

3-Main governate of practice?

*Alexandria

*Cairo-Giza

*Central region

*Delta region

*Lower Egypt

*Upper Egypt

4-Main Field of practice?

*Dementia

*Stroke

*Multiple Sclerosis

*Epilepsy

*Movement disorders

5-Would you recommend PEG for patients with prolonged need of Ryle feeding? * Yes *No

6- In your own practice, what's the main barrier for offering PEG?

*Lack of knowledge about the benefits of PEG

*Financial issues

*Family resistance

*Unavailability of well-trained gastroenterologist

*Neuromuscular disorders

*Headache

*General Neurology

*Others

7- In cases of refusal of care givers, what was their main concern?

*Fear that they will not be able to handle it and provide proper care

* Fear of altered body image

*Fear of complications

*Previous unsuccessful experience

*You are not convinced with its benefit *Others

${ }^{*}$ Avoiding surgical procedures *Others

8-Hove you ever been approached by GIT specialist to suggest or offer PEG for one of your patients? *Yes *No

9-Have you ever attended a lecture or seminar about the benefits and indications of PEG? *Yes *No

10-Have you ever referred a patient to PEG? *Yes *No

11- If yes, How many times did you refer a patient to PEG?

*Less than 5

*5-10 times

*11-20 times

12-What was the main reason for referral?

* Prior positive experience

*More than 20 times

*Family request

${ }^{*}$ Availability

* Low cost

*It was suggested by nutrition or GIT specialist

*Preventing aspiration

*Improving quality of life

*Malnutrition and weight loss

13-What was the most common diagnosis?

*Stroke (Lateral Medullary)

*Stroke (Brain stem)

* Stroke (Middle cerebral artery)

* Stroke (Internal carotid artery)

* Intracerebral hemorrhage

*Dementia

*Multiple Sclerosis

${ }^{*}$ Others

14- How soon do you offer your patients the option of PEG?

*First week

* Second week

*2-4 weeks

*Amyotrophic lateral sclerosis

*Leukodystrophy

*Brain tumor

*Parkinson's disease

*Post-encephalitic sequel

*Others

15- To whom did you refer your patient for PEG?

*General Surgery

${ }^{*}$ Gastroenterology

* Interventional Radiology

*Others

16-What were the most common complications you experienced with your patients referred to PEG?

*Leakage

*Soreness or inflammation 
Table 1 Questionnaire regarding neurologists' experience regarding PEG (Continued)

\begin{tabular}{ll}
\hline Do you agree to participate? *Yes *No & \\
If Yes, please proceed to answer the following questions & *Mortality \\
\hline *Slippage & *Others \\
*Infection & \\
$17-$ How would you like to rate your experience regarding the patient's outcome? & \\
Very unsatisfactory $1-2-3-4-5$ Very satisfactory & \\
$18-$ How would you rate the caregiver satisfaction? & \\
Very unsatisfactory $1-2-3-4-5$ Very satisfactory \\
$19-$ Would you recommend PEG again for your indicated patients? *Yes *No
\end{tabular}

PEG percutaneous endoscopic gastrostomy

experience as "4" while $31(35.23 \%)$ rated their experience as "3," 14 (15.91\%) as "5," and $3(3.41 \%)$ as "2." They were also asked to rate the average of the caregiver satisfaction on a scale from 1-5 (1 being very unsatisfactory experience and 5 being a very satisfactory experience): 36 (40.91\%) rated their experience as "4" while 34 (38.64\%) rated their experience as " 3, " $10(11.36 \%)$ as " 5 , " and $8(9.09 \%)$ as "2."

We also investigated the most common complications experienced with patients referred to PEG (allowing more than one response): the most common complication was leakage in 56 followed by infection in 36, slippage in 21 , soreness or inflammation in 18 , mortality in 1 , and bleeding in 1 . However, 88 (100\%) of neurologists who previously referred patients for PEG stated that they would recommend PEG again for their indicated patients.

\section{Discussion}

Percutaneous endoscopic gastrostomy (PEG) has been a recognized method for prolonged enteral feeding since the 1980s [11], being favorable than nasogastric feeding regarding continuity of feeding and aspiration rates [12]. A study by Hamidon and colleagues confirmed that PEG feeding is more efficient than nasogastric tube feeding in dysphagic stroke patients [13]. The need for PEG has been controversial, yet it has been on the rise for these last few decades in the treatment of patients with chronic neurological disorders especially those suffering from swallowing difficulties that hinder sufficient nutrition and hydration through an oral route. Its main aims

Table 2 Association between years of experience practicing Neurology and number of referral

\begin{tabular}{lllll}
\hline & $\begin{array}{l}\text { Referring } \leq \\
\text { 10 patients }\end{array}$ & $\begin{array}{l}\text { Referring } \\
\mathbf{1 1 - 2 0} \\
\text { patients }\end{array}$ & $\begin{array}{l}\text { Referring }> \\
\mathbf{2 0} \text { patients }\end{array}$ & $\begin{array}{l}\boldsymbol{p} \\
\text { value }\end{array}$ \\
\hline $\begin{array}{l}\text { Neurology } \\
\text { practice }\end{array}$ & 41 & 6 & 8 & 0.01 \\
$\begin{array}{l}\mathbf{1 5} \text { years' } \\
\begin{array}{l}\text { Neurolog' } \\
\text { practice }\end{array}\end{array}$ & 14 & 7 & 12 & \\
\hline
\end{tabular}

are to prevent aspiration pneumonia and maintain proper nutrition $[14,15]$.

To our knowledge, this is the first survey about PEG feeding experience to be done among Egyptian neurologists. The average years of experience of the neurologists who responded to the survey is $15.12 \pm 9.38$ years, with more than $75 \%$ of them working at the university hospitals. With five universities having medical schools, 76\% of the responses came from Cairo and Giza region.

Cerebrovascular disorders were the most common neurological diagnoses to be chosen by the surveyed neurologists in our study, with 117 (54.4\%) choices out of 215 total choices. This goes with many other studies that concluded the superiority of cerebrovascular disorders (30-60\%) to need PEG among patients with neurological disorders mainly due to dysphagia and/or severe bulbar symptoms [15-20]. The second common diagnosis to be chosen was motor neuron disease with 40 (18.6\%) choices, similar to that noted in other studies with the same scope that ranged for $10-30 \%$ of neurological cases $[15,19,21]$. Dementia came as the third choice of diagnoses that need PEG with 27 (12.6\%) choices similar to a previous study by Tominaga and colleagues in 2010 [19].

Eighty-eight percent of our neurologist group referred patients to perform PEG. This raises the question about investigating the different barriers faced by these neurologists in real practice. Out of total 174 responses, 53.5\% attributed to either family resistance or financial reasons as the main barrier against performing PEG to the indicated patients. A recent international study in 2019 revealed a relatively higher percentage regarding these barriers reaching more than $75 \%$ of the cases [22]. The family usually goes against PEG for the mistaken idea about the PEG feeding is burdensome or even dangerous to apply, fearing of the surgical procedure itself, or the inability to handle and provide proper care, or altering body image [23]. This requires compassion and time from the physician and healthcare providers to discuss the rationale and the benefits of PEG feeding [24-26].

Nearly half of the responders, who previously referred patients to perform PEG (44.3\%), stated that they usually 
request it in the first 2-4 weeks after onset of illness. This goes with the guideline of stroke management [27]. Moreover, about two thirds (62.5\%) of these neurologists referred less than 10 patients for PEG feeding. The interesting finding here is that again about two thirds of neurologists who referred patients for PEG were younger neurologists practicing Neurology for less than 15 years. This was significantly higher than those with longer experience in practicing Neurology. This gives us the impression that PEG feeding is getting more recognition in Neurology practice over the last couple of decades, with the younger generations being more enthusiastic and daring.

However, the real problem revealed here was that about $18 \%$ of our surveyed neurologists stated that they lack the sufficient knowledge about the benefits of PEG feeding. Only $22 \%$ previously attended a lecture or seminar about the benefits and indications of PEG, despite that $66 \%$ of our sample were previously approached by a GIT specialist to suggest or offer PEG for their patients. Few studies revealed similar results regarding the physicians' awareness of PEG feeding benefits [28]. This highlights the gap in neurologists' knowledge on PEG feeding for indicated patients in neurological practice. Training sessions targeting neurologists on the benefits of PEG is very required.

Questioning the experience of the surveyed neurologists regarding patients' outcome on a scale from 1 to 5 , about two thirds $(64.4 \%)$ of them had a very satisfactory experience. This reflects the growing recognition of the importance and benefits of PEG feeding among Egyptian neurologists, as we mentioned lately. This experience is globally adopted by neurologists and has been studied in some other studies over the last 20 years $[17,18,22,26$, 28]. Similarly, they reported a very satisfactory experience to the caregivers in over half $(52.3 \%)$ of the cases they referred to perform PEG. These results indeed encourage neurologists to recommend PEG feeding when indicated. Studies over the last few years also confirmed similar results with the majority of caregivers of patients with PEG feeding reported relief and satisfaction regarding their experience with PEG in their patients in around $60 \%$ of the cases $[29,30]$.

Being a relatively simple procedure, the associated mortality related to PEG insertion is very low (0.5$4.5 \%$ ), and complications can be considered trivial [ 30 , 31]. We received 133 responses regarding complications from our 88 neurologists who previously referred their patients to perform PEG. The most common complication reported was leakage in $42.1 \%$ followed by infection in $27.1 \%$, slippage in $15.8 \%$, and soreness or inflammation in $14.3 \%$. In general, a small amount of leakage of secretions is considered normal, yet actual leakage must be confirmed to be gastric secretion and/or content [32,
33]. Although the reported incidence of leakage used to be much lower in older studies, it is in fact a much more common complication as reported in more recent studies. Several factors that can increase the risk of leakage have been identified, including gastric hypersecretion and excessive cleansing with hydroperoxide, as well as other specific factors related to the patient that inhibit wound healing such as poor baseline nutritional status, diabetes, and immunodeficiency [26, 31, 34].

On the other hand, many studies reported infection as the most common complication with rates around 20$30 \%$ of the cases $[31,33,35]$, which is similar to our results. In some older studies, it was reported to be as high as $65 \%[36,37]$. Once again, mild redness around the tube insertion site is common due to tube movement which is considered acceptable; however, more severe redness, purulent discharge, and signs of systemic infection must raise the possibility of wound infection $[26$, 32-35].

Despite these complications and their frequency to happen, all our surveyed neurologists, who previously referred a patient to perform PEG, were confident to rerecommend PEG feeding for their future indicted patients. This is a quite impressive and encouraging result.

\section{Conclusion}

PEG provides a safe effective way for enteral feeding in patients with long-term dysphagic neurological patients. Based on our study, we recommend that PEG should be more encouraged in indicated neurological cases. Scientific sessions targeting neurologists and public awareness about the benefits of PEG and its relatively infrequent complications are highly demanded.

\section{Abbreviations}

NGT: Nasogastric tube; PEG: Percutaneous endoscopic gastrostomy

\section{Acknowledgements}

The authors would like to thank all fellow neurologists from all over Egypt who kindly offered their precious time and participated in our survey.

\section{Authors' contributions}

SF, MF, SG, AS, and KA made substantial contributions to the conception and design of the study; MF performed the acquisition of the data; SF, MF, AS, and KA participated in the analysis and interpretation of the data; MF, SG, and KA have been involved in drafting the manuscript or revising it critically for important intellectual content. All authors agreed to be accountable for all aspects of the work in ensuring that questions related to the accuracy or integrity of any part of the work are appropriately investigated and resolved. The authors read and approved the final manuscript.

\section{Funding}

None

\section{Availability of data and materials}

The datasets generated and analyzed during the current study are not publicly available due to institutional limitations, yet they are available from the corresponding author on reasonable request. 


\section{Ethics approval and consent to participate}

The research was approved by the Neurology Department Ethical Committee, Ain Shams University, in June 2020; however, reference number is not applicable as it is not provided by the institute.

All participating neurologists provided their written approval to participate in this survey.

\section{Consent for publication}

Not applicable

\section{Competing interests}

The authors declare that they have no competing interests.

\section{Author details}

${ }^{1}$ Neurology Department, Faculty of Medicine, Ain Shams University, Cairo, Egypt. ${ }^{2}$ Neurology Department, Helwan University School of Medicine, Cairo, Egypt.

Received: 8 September 2020 Accepted: 2 October 2020

Published online: 09 October 2020

\section{References}

1. Buchholz DW. Dysphagia associated with neurological disorders. Acta Otorhinolaryngol Belg. 1994;48(2):143-55.

2. González-Fernández M, Ottenstein L, Atanelov L, Christian AB. Dysphagia after stroke: an overview. Curr Phys Med Rehabil Rep. 2013;1(3):187-96.

3. Steinhagen V, Grossmann A, Benecke R, Walter U. Swallowing disturbance pattern relates to brain lesion location in acute stroke patients. Stroke. 2009; 40:1903-6.

4. Martens L, Cameron T, Simonsen M. Effects of a multidisciplinary management program on neurologically impaired patients with dysphagia. Dysphagia. 1990;5(3):147-51.

5. Stroud M, Duncan H, Nightingale J. Guidelines for enteral feeding in adult hospital patients. Gut. 2003:52(Suppl 7):vii1-vii12.

6. Gomes CAR Jr, Andriolo RB, Bennett C, Lustosa SAS, Matos D, Waisberg DR, et al. Percutaneous endoscopic gastrostomy versus nasogastric tube feeding for adults with swallowing disturbances. Cochrane Database Syst Rev. 2015;2015(5):CD008096.

7. Gieniusz M, Sinvani L, Kozikowski A, Patel V, Nouryan C, Williams MS, et al. Percutaneous feeding tubes in individuals with advanced dementia: are physicians "choosing wisely"? J Am Geriatr Soc. 2018;66(1):64-9.

8. Shega JW, Hougham GW, Stocking CB, Cox-Hayley D, Sachs GA. Barriers to limiting the practice of feeding tube placement in advanced dementia. J Palliat Med. 2003;6(6):885-93

9. Teno J, Meltzer DO, Mitchell SL, Fulton AT, Gozalo P, Mor V. Type of attending physician influenced feeding tube insertions for hospitalized elderly people with severe dementia. Health Aff (Millwood). 2014;33(4):675-82.

10. Jaafar MH, Mahadeva S, Tan KM, Tan MP. Attitudes of health care professionals towards gastrostomy feeding in older adults in Malaysia. Int $\rfloor$ Gerontol. 2015;9(1):40-5.

11. Ponsky JL, Gauderer MW. Percutaneous endoscopic gastrostomy: indications, limitations, techniques, and results. World J Surg. 1989;13(2): 165-70.

12. Löser C, Wolters S, Fölsch UR. Enteral long-term nutrition via percutaneous endoscopic gastrostomy (PEG) in 210 patients: a four-year prospective study. Dig Dis Sci. 1998:43(11):2549-57.

13. Hamidon BB, Abdullah SA, Zawawi MF, Sukumar N, Aminuddin A, Raymond AA. A prospective comparison of percutaneous endoscopic gastrostomy and nasogastric tube feeding in patients with acute dysphagic stroke. Med J Malaysia. 2006:61(1):59-66.

14. Britton JE, Lipscomb G, Mohr PD, Rees WD, Young AC. The use of percutaneous endoscopic gastrostomy (PEG) feeding tubes in patients with neurological disease. J Neurol. 1997;244(7):431-4.

15. Zalar AE, Guédon C, Piskorz EL, Basso AS, Ducrotté P. Percutaneous endoscopic gastrostomy in patients with neurological diseases. Results of a prospective multicenter and international study. Acta Gastroenterol Latinoam. 2004;34(3):127-32.

16. James A, Kapur K, Hawthorne AB. Long-term outcome of percutaneous endoscopic gastrostomy feeding in patients with dysphagic stroke. Age Ageing. 1998;27(6):671-6.
17. Nicholson FB, Korman MG, Richardson MA. Percutaneous endoscopic gastrostomy: a review of indications, complications and outcome. Gastroenterol Hepatol. 2000;15:21-5.

18. Luman W, Kwek KR, Loi KL, Chiam MA, Cheung WK, Ng HS. Percutaneous endoscopic gastrostomy--indications and outcome of our experience at the Singapore General Hospital. Singapore Med J. 2001;42(10):460-5.

19. Tominaga N, Shimoda R, Iwakiri R, Tsuruoka N, Sakata Y, Hara H, et al. Low serum albumin level is risk factor for patients with percutaneous endoscopic gastrostomy. Intern Med. 2010;49:2283-8.

20. Arora G, Rockey D, Gupta S. High In-hospital mortality after percutaneous endoscopic gastrostomy: results of a nationwide population-based study. Clin Gastroenterol Hepatol. 2013;11:1437-44.

21. Shimizu T, Hanaoka T, Hayashi H, Inoue H, Imamura K, Oyanagi K. Percutaneous endoscopic gastrostomy in patients with intractable neurological diseases-retrospective study of the indication, complication and prognosis. Rinsho Shinkeigaku. 2007:47:565-70.

22. Mohandas N, Kumar R, Leelakrishnan V, Sharma S, Aparanji K. International survey of physicians' perspectives on percutaneous endoscopic gastrostomy tube feeding in patients with dementia and review of literature. Cureus. 2019;11(4):e4578.

23. Lin LC, Li MH, Watson R. A survey of the reasons patients do not choose percutaneous endoscopic gastrostomy/jejunostomy (PEG/PEJ) as a route for long-term feeding. J Clin Nurs. 2011;20(5-6):802-10.

24. Hanson LC, Carey TS, Caprio AJ, Lee TJ, Ersek M, Garrett J, et al. Improving decision-making for feeding options in advanced dementia: a randomized controlled trial. J Am Geriatr Soc. 2011:59(11):2009-16.

25. The Ad-Hoc PEG Tube Study Group, Beaulieu PM, Bochanski PG, Clark CE, Doherty K, Frank JW, Howland J, et al. When to recommend a PEG tube: a decision tree for clinicians from a Catholic perspective. Linacre Q. 2012;79(1): 25-40.

26. ljaopo EO, ljaopo RO. Tube feeding in individuals with advanced dementia: a review of its burdens and perceived benefits. J Aging Res. 2019;2019: 7272067.

27. Jauch EC, Saver JL, Adams HP Jr, Bruno A, Connors JB, Demaerschalk BM, et al. Guidelines for the early management of patients with acute ischemic stroke: a guideline for healthcare professionals from the American Heart Association/American Stroke Association. Stroke. 2013:44(3):870-947.

28. Hanson LC, Garrett JM, Lewis C, Phifer N, Jackman A, Carey TS. Physicians' expectations of benefit from tube feeding. J Palliat Med. 2008;11(8):1130-4.

29. Nakanishi M, Hattori K. Percutaneous endoscopic gastrostomy (PEG) tubes are placed in elderly adults in Japan with advanced dementia regardless of expectation of improvement in quality of life. J Nutr Health Aging. 2014; 18(5):503-9.

30. Nunes G, Santos CA, Santos C, Fonseca J. Percutaneous endoscopic gastrostomy for nutritional support in dementia patients. Aging Clin Exp Res. 2016:28(5):983-9.

31. Blumenstein I, Shastri YM, Stein J. Gastroenteric tube feeding: techniques, problems and solutions. World J Gastroenterol. 2014;20(26):8505-24.

32. Rahnemai-Azar AA, Rahnemaiazar AA, Naghshizadian R, Kurtz A, Farkas DT. Percutaneous endoscopic gastrostomy: indications, technique, complications and management. World J Gastroenterol. 2014;20(24):7739-51.

33. Pih GY, Na HK, Ahn JY, Jung KW, Kim DH, Lee JH, et al. Risk factors for complications and mortality of percutaneous endoscopic gastrostomy insertion. BMC Gastroenterol. 2018;18(1):101.

34. Sarkar P, Cole A, Scolding NJ, Rice CM. Percutaneous endoscopic gastrostomy tube insertion in neurodegenerative disease: a retrospective study and literature review. Clin Endosc. 2017:50(3):270-8.

35. Inanç Y, Gökce M, Tuncel D, İnanç Y, Özçekic Demirhan S, Bavli S. Percutaneous endoscopic gastrostomy in neurology intensive care unit. Int J Surg Med. 2018;4(1):33-5.

36. Preclik G, Grüne S, Leser HG, Lebherz J, Heldwein W, Machka K, Holstege A, Kern W. Prospective, randomised, double blind trial of prophylaxis with single dose of co-amoxiclav before percutaneous endoscopic gastrostomy. BMJ. 1999:319(7214):881-4

37. Vanis N, Saray A, Gornjakovic S, Mesihovic R. Percutaneous endoscopic gastrostomy (PEG): retrospective analysis of a 7-year clinical experience. Acta Inform Med. 2012;20(4):235-7.

\section{Publisher's Note}

Springer Nature remains neutral with regard to jurisdictional claims in published maps and institutional affiliations. 